\title{
Ultra-shallow seismic imaging of the top of the saturated zone
}

\author{
Steven D. Sloan, ${ }^{1}$ Georgios P. Tsoflias, ${ }^{2}$ and Don W. Steeples ${ }^{2}$ \\ Received 24 February 2010; accepted 5 March 2010; published 8 April 2010.
}

[1] We collected ultra-shallow seismic-reflection data to image the near-surface stratigraphy of a Kansas River point bar. We were successful in identifying a discontinuous clay layer and the top of the saturated zone at depths of 0.95 and $1.4 \mathrm{~m}$. Seismic walkaway data collected using various .22-caliber ammunition show that decreased source energy is necessary to generate higher frequencies and prevent clipping of critical near-offset traces needed to identify ultra-shallow reflections. The seismic reflections exhibited average normal moveout velocities of $180-195 \mathrm{~m} / \mathrm{s}$ with dominant frequencies of $200-450 \mathrm{~Hz}$. Coincident subsurface features were also imaged using $200-\mathrm{MHz}$ ground-penetrating radar. This study presents the shallowest seismic reflection from the top of the saturated zone reported in the literature to date and further demonstrates the potential of using seismic-reflection methods for ultra-shallow imaging of the subsurface as a stand-alone tool or in conjunction with other high-resolution geophysical techniques. Citation: Sloan, S. D., G. P. Tsoflias, and D. W. Steeples (2010), Ultra-shallow seismic imaging of the top of the saturated zone, Geophys. Res. Lett., 37, L07405, doi:10.1029/2010GL043034.

\section{Introduction}

[2] Geophysical techniques such as ultra-shallow seismic reflection (USR) and ground-penetrating radar (GPR) are commonly used to image the shallow subsurface for engineering, hydrogeologic, and environmental applications and may be preferred to drilling in some instances where noninvasive methods are necessary. Although both GPR and USR can image coincident volumes, each responds to different subsurface properties. GPR employs electromagnetic (EM) waves, which respond to changes in electrical and magnetic subsurface properties. Seismic reflections occur as a result of changes in density and seismic velocity of geologic materials. It is possible for a seismic reflection to occur at an interface that is not detected by GPR and vice versa; however, coincident USR and GPR reflections often occur at geologic boundaries with changing acoustic and dielectric properties, yielding comparable images. GPR is commonly used for imaging depths less than $10 \mathrm{~m}$ due to the rapid attenuation of EM waves in geologic environments. Seismic methods are typically used to image greater depths because of the difficulty in generating and detecting the high frequencies necessary to resolve ultra-shallow reflectors.

\footnotetext{
${ }^{1}$ Engineer Research and Development Center, U.S. Army Corps of Engineers, Vicksburg, Mississippi, USA. USA.

Department of Geology, University of Kansas, Lawrence, Kansas,

Copyright 2010 by the American Geophysical Union. 0094-8276/10/2010GL043034
}

Despite the challenges, advances in high-resolution USR techniques have led to imaging within the upper $10 \mathrm{~m}$ of the subsurface [Steeples and Miller, 1990] and even as shallow as $63 \mathrm{~cm}$ [Baker et al., 1999].

[3] Near-surface seismic reflection methods have been used for an array of applications, including determining depth to bedrock or the water table, void detection, delineating near-surface stratigraphy, fault identification, and identifying contaminant sinks or pathways, to name a few [Steeples and Miller, 1990]. Accurately imaging ultra-shallow depths (less than $20 \mathrm{~m}$ ) using seismic methods provides another tool to complement other techniques, such as GPR, electromagnetic, electrical, etc., or to use when other methods are not successful. Surface seismic methods are non-invasive and may be desired when characterizing contaminated areas where the installation of monitoring wells or boreholes may exacerbate the problem by providing conduits for contaminants to flow from one stratum to another.

[4] This study presents the results of a USR survey designed to image the near-surface stratigraphy of a river point bar, including a discontinuous clay layer at a depth of less than one meter and the top of the saturated zone (TSZ) at $1.4 \mathrm{~m}$ deep. Previous studies have successfully imaged the TSZ at ultra-shallow depths [Birkelo et al., 1987; Bachrach and Nur, 1998a, 1998b; Baker et al., 1999; Baker et al., 2000; Sloan et al., 2007], but none have been less than $2 \mathrm{~m}$ deep. The TSZ reflection imaged by this study occurs at a two-way travel time of $15 \mathrm{~ms}$ and $1.4 \mathrm{~m}$ in depth, making this the shallowest TSZ reflection reported in the literature to date. Observing reflections at very shallow depths requires dense sampling of the near-surface wavefield, necessitating source and receiver spacing as small as $5-10 \mathrm{~cm}$, to ensure events are sufficiently sampled to be identified and to prevent the misinterpretation of spatially aliased signal. In general, relatively high frequencies and low seismic velocities are also necessary to differentiate reflections from other events, such as refractions, and prevent reflections from being masked by other wave trains, such as the airwave or ground roll.

[5] Coincident shallow features were also imaged by 200-MHz GPR data, which correlated well with the seismic data collected along the same line. Previously reported studies have discussed the coincident use of seismic and GPR methods [Cardimona et al., 1998; Bachrach and Nur, 1998b; Baker et al., 2001; Sloan et al., 2007], demonstrating the ability to image concurrent features and improve geologic interpretations. Due to the response of each method to different physical properties, field site conditions may not be suitable for the joint use of both methods. Although GPR data can be acquired more efficiently, the depth of penetration is severely limited in clay-rich environments due to rapid signal attenuation. The ability to seismically image depths comparable to GPR provides another high-resolution 


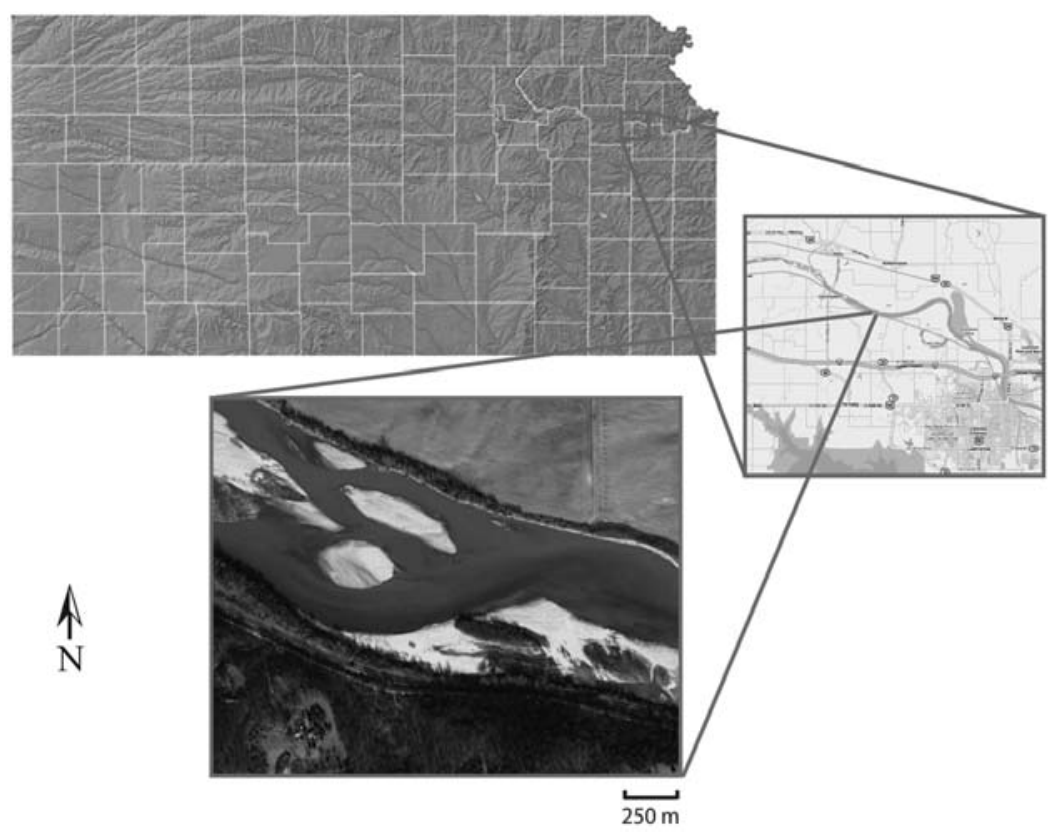

Figure 1. Site map of the sandbar location on the bank of the Kansas River. The position of the seismic line is indicated by the red marking. Coordinates of the survey area are Latitude $39^{\circ} 2^{\prime} 0^{\prime \prime} \mathrm{N}$ and Longitude $95^{\circ} 21^{\prime} 16^{\prime \prime} \mathrm{W}$.

site-characterization option for the near-surface geophysicist when other methods are not suitable.

\section{Geologic Setting}

[6] High-resolution seismic reflection lines were acquired at a point bar on the Kansas River located near Lecompton, Kansas (Figure 1). Surface geology includes alternating Pennsylvanian-aged shale and marine limestone layers of the Kanwaka Shale, Oread Limestone, and Lawrence Formation overlain by Quaternary alluvium deposits. The sandbar itself consists of a fining-upward sequence of medium- to coarse-grained sands typical of point bar deposits. A hand-dug hole at the site revealed $0.95 \mathrm{~m}$ of medium- to coarse-grained sand overlying a thin clay layer approximately $10 \mathrm{~cm}$ thick. The water table was located at a depth of $1.4 \mathrm{~m}$.

\section{Data Acquisition and Processing}

[7] Two-dimensional, 72-fold common-midpoint (CMP) $\mathrm{P}$-wave seismic-reflection data were acquired using 144 Mark Products 100-Hz L-40A2 vertical-component geophones planted at $10-\mathrm{cm}$ intervals. The source was a.22caliber rifle firing single short rounds into $\sim 15-\mathrm{cm}$ deep holes at $10-\mathrm{cm}$ intervals centered between adjacent geophones. Source holes were punched one at a time for each shot to prevent hole collapse and infill. Data were recorded by two 72-channel Geometrics StrataView seismographs with 24-bit A/D conversion using a 0.25 -ms sampling interval and 256-ms trace lengths.

[8] Data were processed using common CMP processing techniques, including geometry definition, CMP sorting, velocity analysis, normal-moveout (NMO) corrections, CMP stacking, bandpass filtering and automatic gain control (AGC). Early muting was not applied to confirm that the events are not artifacts due to clipping [Sloan et al., 2008] or incorrect mute tapers. Figure 2 illustrates a CMP gather with AGC only (Figure 2a), after bandpass filtering and AGC (Figure 2b), and after NMO corrections and 7\% stretchmute limit (Figure 2c). NMO-correction velocities ranged from $175-195 \mathrm{~m} / \mathrm{s}$ with an average of $\sim 180 \mathrm{~m} / \mathrm{s}$ across the

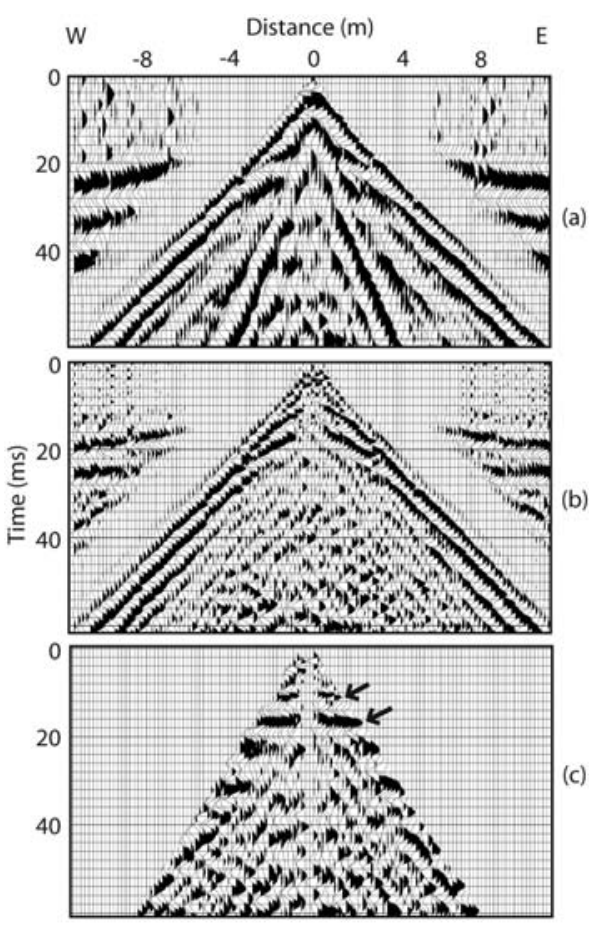

Figure 2. CMP gather displayed (a) without processing, (b) with a bandpass filter and 30-ms AGC window, and (c) after NMO correction with a 7\% stretch mute. The reflections are located at $\sim 10.5$ and $15 \mathrm{~ms}$ in Figure $2 \mathrm{~b}$ and $2 \mathrm{c}$, indicated by the arrows. 

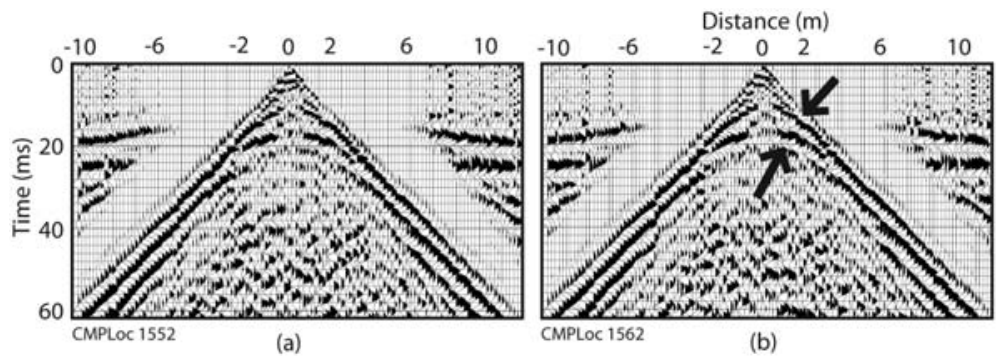

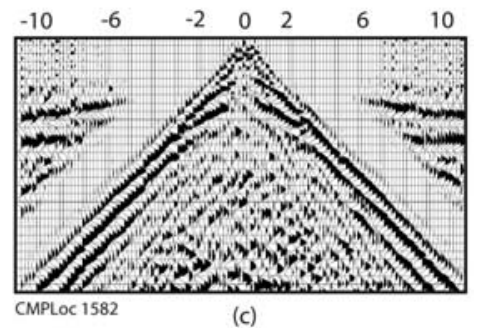

(c)

Figure 3. CMP gathers with the discontinuous clay reflection occurring at $\sim 10.5 \mathrm{~ms}$ and the TSZ reflection at $\sim 18 \mathrm{~ms}$. The TSZ refraction is located at $\sim 15 \mathrm{~ms}$. Data are displayed with a time-variant $150-700 \mathrm{~Hz}$ bandpass filter and a 30-ms AGC window.

line for the discontinuous clay reflection and $\sim 195 \mathrm{~m} / \mathrm{s}$ for the TSZ reflection. A very aggressive stretch mute was chosen based on the severe wavelet stretch associated with low-velocity reflections [Miller, 1992] and was selected to intercept the reflection prior to the point where the reflection and direct wave merge ( $\pm 1.0 \mathrm{~m}$ offset) to ensure that directwave energy did not contribute to the stacked reflection. The dominant frequencies of the clay and TSZ reflections are approximately 200 and $450 \mathrm{~Hz}$, respectively. Bandpass filter parameters included a time-variant pass band of 150 $700 \mathrm{~Hz}$ with 16 and $12 \mathrm{~dB}$ rolloff slopes on the low and high sides, respectively. A 30-ms AGC window was also applied. GPR data were acquired using a pulseEKKO 100 system with $200-\mathrm{MHz}$ antennae, station interval of $5 \mathrm{~cm}$, and a transmitter-to-receiver offset of $1 \mathrm{~m}$.

\section{Results and Discussion}

[9] Figure 3 displays three CMP gathers from multiple locations along the survey line. The direct wave and a refraction interpreted to be from the clay layer are evident, and the reflections can clearly be identified as the hyperbolic events at 10.5 and $15 \mathrm{~ms}$, identified by the arrows. The direct wave and clay layer reflection exhibit velocities of $180 \mathrm{~m} / \mathrm{s}$ which, combined with a two-way travel time of $10.5 \mathrm{~ms}$, yield an approximate depth of $0.95 \mathrm{~m}$ to the re- flector. Figure 4a shows the CMP-stacked section; the discontinuous clay layer reflection is located at $10.5 \mathrm{~ms}$ and ranges in depth from $\sim 0.9-1.0 \mathrm{~m}$, which correlates well with the individual gathers. Refraction analysis yielded an average velocity of $1389 \mathrm{~m} / \mathrm{s}$ and intercept time of $10.1 \mathrm{~ms}$, which leads to a refractor depth of approximately $0.91 \mathrm{~m}$. These results indicate that the refractor is the clay layer as the water table is $1.4 \mathrm{~m}$ deep, which would yield a markedly increased intercept time of $\sim 15.4 \mathrm{~ms}$. The refractor depth of $0.91 \mathrm{~m}$ correlates well with the clay reflector depth of $0.95 \mathrm{~m}$.

[10] To image seismic reflections in the upper two meters of the subsurface, both high frequencies $(>400 \mathrm{~Hz})$ and relatively low velocities $(<300 \mathrm{~m} / \mathrm{s})$ are required [Baker et al., 1999]. Figure 5 shows walkaway test records and corresponding amplitude spectra collected with .22-caliber short (Figure 5a) and long-rifle ammunition (Figure 5b). Short ammunition produces less energy and, therefore, less non-linear deformation of the impact area, thereby yielding higher frequencies. The short ammunition produces a relatively flat frequency response across a bandwidth of $\sim 250$ $750 \mathrm{~Hz}$ for the shot gather. The long-rifle data yields frequencies that peak at $\sim 500 \mathrm{~Hz}$, but rapidly decay on either side.

[11] A source that produces less energy yields higher frequencies, but it also offers the advantage of overdriving fewer near-offset geophones and producing fewer clipped

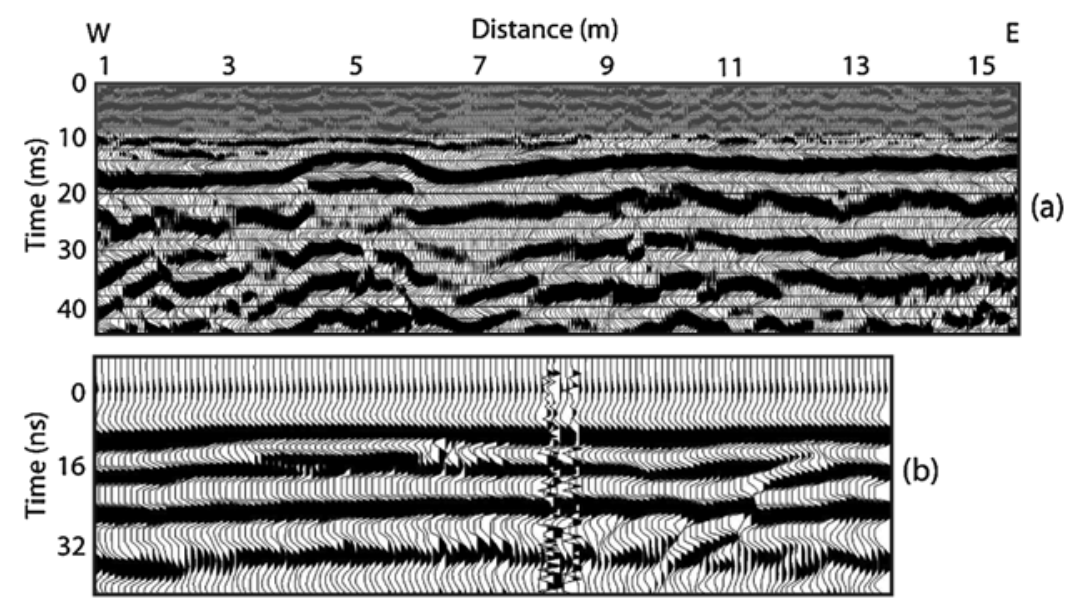

Figure 4. (a) CMP-stacked seismic section and (b) 200-MHz GPR section. The seismic reflections from the discontinuous clay layer and TSZ are present at $\sim 10.5 \mathrm{~ms}$ and $15 \mathrm{~ms}$, respectively, with a TSZ multiple at approximately $30 \mathrm{~ms}$. The grayed box on the seismic section encompasses coherently stacked direct-wave and refraction energy that would have been removed by an early mute. 

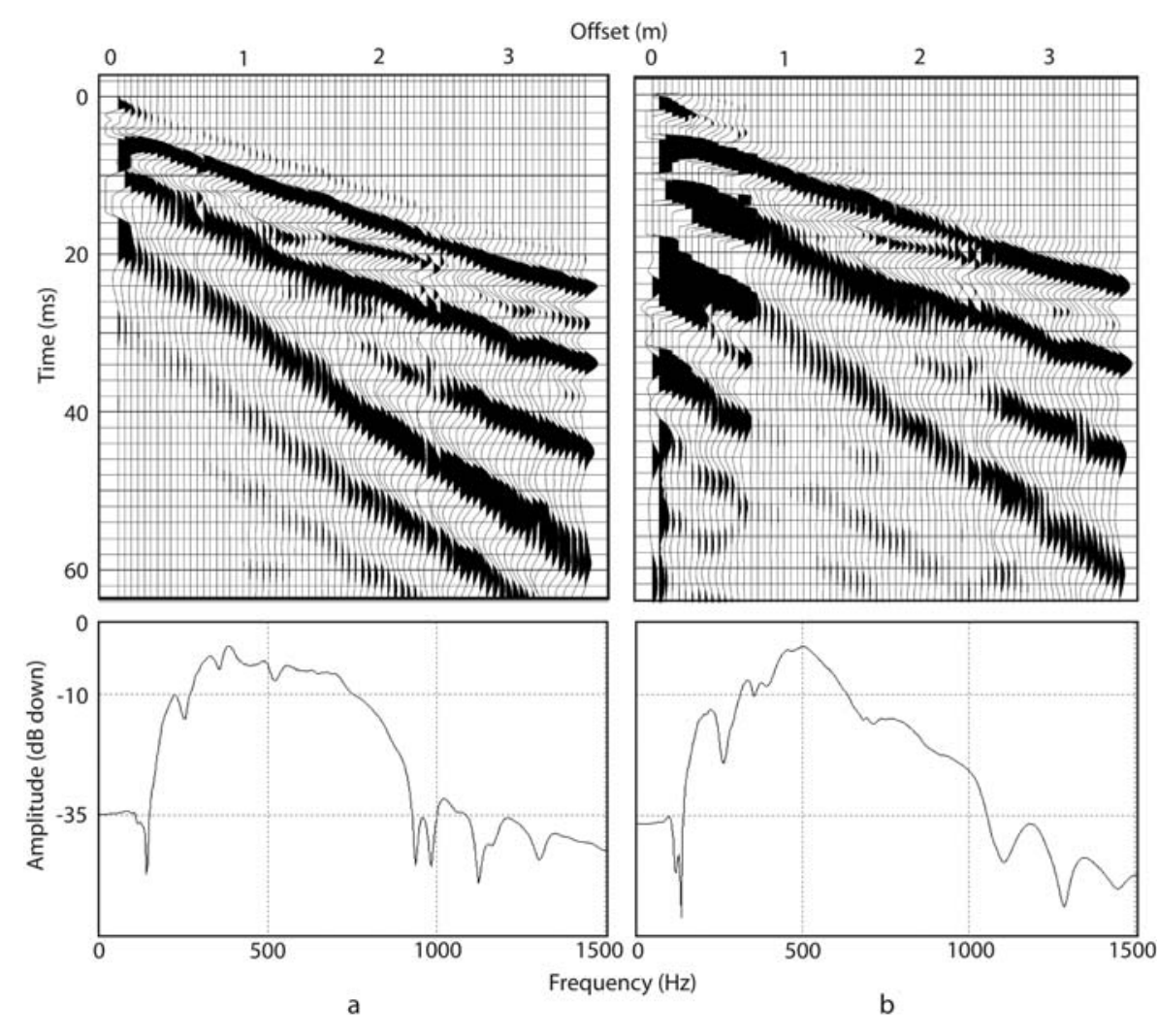

Figure 5. Walkaway-test data and associated frequency-amplitude spectra for data acquired with (a) .22-caliber short and (b) long-rifle ammunition. The first two traces are clipped in Figure 5a, compared to seven traces in Figure 5b, which would render $70 \%$ of the TSZ reflection unusable if CMP data were acquired with long-rifle ammunition. Higher amplitudes are also evident in the $250-750-\mathrm{Hz}$ frequency range of the short-ammunition spectra (Figure $5 \mathrm{a}$ ).

traces. The TSZ reflection is coherent from offsets of $\pm 1.0 \mathrm{~m}$ in CMP records. The short ammunition clipped the first and second traces $(20 \mathrm{~cm})$ in the walkaway data. The long-rifle ammunition clipped traces out to a source-to-receiver offset of $0.7 \mathrm{~m}$, effectively eliminating $70 \%$ of traces containing reflection information and making the identification of the TSZ reflection nearly impossible. To further reduce the chances of clipping, the source was positioned between adjacent geophones instead of inline with each geophone. Although this put the nearest geophones at $5 \mathrm{~cm}$ away from the source, the next geophones were $15 \mathrm{~cm}$ away instead of $10 \mathrm{~cm}$, potentially leading to fewer clipped traces.

[12] The TSZ reflection can be seen at $\sim 15 \mathrm{~ms}$ and a multiple is present at approximately $30 \mathrm{~ms}$ (Figure 4a). There is a noticeable "bump" between offsets of 4.25 and $6 \mathrm{~m}$ along the TSZ reflection (Figure 4a). This feature is interpreted to be a fluvial depositional feature, such as a clay lens or other fine-grained material. The presence of fine-grained material could create a perched water table, which would explain the temporal shift of the TSZ reflection. A coincident $200 \mathrm{MHz}$ GPR line is displayed in Figure 4b for comparison of imaged subsurface features. A similar anomaly was imaged by the GPR, and corresponds almost identically spatially, ranging from approximately $3.5-6.5 \mathrm{~m}$ along the profile and at $\sim 12$ ns time (Figure $4 \mathrm{~b}$ ). The TSZ reflection is at $\sim 16 \mathrm{~ns}$ in the GPR section. We recognize that interference of direct radar wave arrivals makes interpretation of the top $1 \mathrm{~m}$ ambiguous. Unfortunately, the GPR data were acquired using a sub-optimal transmitter-receiver off- set distance and the direct wave occurs at or near the same time as the reflections of interest, making it very difficult to accurately interpret the shallowest section of the GPR data. However, the corresponding features imaged by both seismic and GPR methods increase our confidence that these shallow features are not a processing artifact and that they are representative of the subsurface.

\section{Conclusions}

[13] This work demonstrates the capability of USR methods to image a stratigraphic reflection and the TSZ at ultra-shallow depths and provides additional evidence of the ability to image the shallow subsurface at resolutions comparable to other high-resolution geophysical methods. The discontinuous clay layer was imaged at a depth of $0.95 \mathrm{~m}$ by using a source capable of generating frequencies up to $750 \mathrm{~Hz}$ while minimizing the clipping of critical near-offset traces. Due to the relatively low seismic velocities and high frequencies at the site, the clay layer and TSZ reflections are easily identified as coherent events unobscured by other wave trains. The reflections exhibited NMO velocities of $\sim 180$ and $195 \mathrm{~m} / \mathrm{s}$ and a dominant frequency of 200 and $450 \mathrm{~Hz}$, yielding a resolution potential as small as $10 \mathrm{~cm}$. A spatially coincident depositional feature was imaged by both the seismic and GPR, which is likely causing a localized perched water table and subsequent temporal shift in the TSZ reflection. The TSZ was imaged at a depth of $1.4 \mathrm{~m}$, making this the shallowest seismically recorded TSZ reflec- 
tion to date. Proper source selection is paramount in USR surveys as even a small change in ammunition selection for the same caliber rifle was the difference in successfully identifying the clay layer reflection. In the proper geologic setting, ultra-shallow seismic methods can be used in conjunction with other geophysical techniques to improve understanding of subsurface properties or to replace nonsuitable methods, providing geophysicists with another option when working in the shallow subsurface.

[14] Acknowledgments. The authors wish to thank Gerard Czarnecki, Robert Eslick, Jon Jarvis, and Ramzey Al-Zayer for their efforts in the field. Permission to publish this paper was granted by Director, Geotechnical and Structures Laboratory, U.S. Army Engineer Research and Development Center.

\section{References}

Bachrach, R., and A. Nur (1998a), High-resolution shallow-seismic experiments in sand, Part 1: Water table, fluid flow, and saturation, Geophysics, 63, 1225-1233, doi:10.1190/1.1444423.

Bachrach, R., and A. Nur (1998b), Same wavelength GPR and ultra shallow seismic reflection on a river point bar: Sand stratigraphy and water table complexity, SEG Expanded Abstr., 17, 840-843, doi:10.1190/ 1.1820617 .

Baker, G. S., C. Schmeissner, D. W. Steeples, and R. G. Plumb (1999), Seismic reflections from depths of less than two meters, Geophys. Res. Lett., 26, 279-282, doi:10.1029/1998GL900243.
Baker, G. S., D. W. Steeples, C. Schmeissner, and K. T. Spikes (2000), Ultrashallow seismic reflection monitoring of seasonal fluctuations in the water table, Environ. Eng. Geosci., 6, 271-277.

Baker, G. S., D. W. Steeples, C. Schmeissner, M. Pavlovic, and R. Plumb (2001), Near-surface imaging using coincident seismic and GPR data, Geophys. Res. Lett., 28, 627-630, doi:10.1029/2000GL008538.

Birkelo, B. A., D. W. Steeples, R. D. Miller, and M. A. Sophocleous (1987), Seismic reflection study of a shallow aquifer during a pumping test, Ground Water, 25, 703-709, doi:10.1111/j.1745-6584.1987.tb02211.x.

Cardimona, S., W. P. Clement, and K. Kadinsky-Cade (1998), Seismic reflection and ground penetrating radar imaging of a shallow aquifer, Geophysics, 63, 1310-1317, doi:10.1190/1.1444432.

Miller, R. D. (1992), Normal moveout stretch mute on shallow-reflection data, Geophysics, 57, 1502-1507, doi:10.1190/1.1443217.

Sloan, S. D., G. P. Tsoflias, D. W. Steeples, and P. D. Vincent (2007), Highresolution ultra-shallow subsurface imaging by integrating near-surface seismic reflection and ground-penetrating radar data in the depth domain, J. Appl. Geophys., 62, 281-286, doi:10.1016/j.jappgeo.2007.01.001.

Sloan, S. D., D. W. Steeples, and P. E. Malin (2008), Acquisition and processing pitfall associated with clipping near-surface seismic reflection traces, Geophysics, 73, W1-W5, doi:10.1190/1.2807051.

Steeples, D. W., and R. D. Miller (1990), Seismic-reflection methods applied to engineering, environmental, and ground-water problems, in Geotechnical and Environmental Geophysics, vol. 1, Invest. in Geophys., vol. 5, edited by S. H. Ward, pp. 1-30, Soc. of Explor. Geophys., Tulsa, Okla.

S. D. Sloan, Engineer Research and Development Center, U.S. Army Corps of Engineers, 3909 Halls Ferry Rd., CEERD-GS-S, Vicksburg, MS 39180, USA. (steven.d.sloan@usace.army.mil)

D. W. Steeples and G. P. Tsoflias, Department of Geology, University of Kansas, Room 120 Lindley Hall, 1475 Jayhawk Blvd., Lawrence, KS 66045, USA. (don@ku.edu, tsoflias@ku.edu) 